\title{
Energy consumption and greenhouse gas emissions of zucchini (Cucurbita pepo L.) cultivated in hydroponic greenhouses in the western region of Portugal
}

\author{
F.J. Baptistaa, L.L. Silva and D. Murcho
}

Departamento de Engenharia Rural, ECT, and Instituto de Ciências Agrárias e Ambientais Mediterrânicas (ICAAM), Universidade de Évora, Évora, Portugal.

\begin{abstract}
In recent years, there has been a significant increase in the consumption of zucchini (Cucurbita pepo L.) in Portugal, which has led to increased production of this vegetable. There is still a deficit of production in winter, but, in summer, production is higher than demand, allowing exportation. At present, there is a positive ratio between zucchini annual exportation/importation values. This means that it is an attractive crop for farmers, especially in the western region of Portugal, which has a microclimate favourable for this crop. The mild winter conditions of the region allow crop growth in unheated greenhouses, which is an advantage for reducing production costs and energy consumption compared with other regions. Crop productivity, either in soil or hydroponics, has increased through the use of better production techniques, modern fertigation systems and new and more productive cultivars. Several improvements in technology and crop practices may now contribute to increased resource-use efficiency, decreasing the negative environmental impact sometimes associated with greenhouse production. The main objective of this work was to evaluate the energy consumption (direct and indirect) and the greenhouse gas (GHG) emissions of greenhouse zucchini produced in the western region of Portugal. All the data were obtained through questionnaires performed directly with growers, which have been previously selected as representative of crop practices and greenhouse type in the region. The results show total energy consumption varying between 4.69 and $6.57 \mathrm{GJ} \mathrm{t}^{-1}$, the electricity used for irrigation making up the largest contribution, followed by the greenhouse material and fertilizers. With this work, the most important inputs were identified, allowing the proposal of alternative measures to improve efficiency and sustainability.
\end{abstract}

Keywords: hydroponics, energy, Mediterranean conditions

\section{INTRODUCTION}

In recent years, there has been a significant increase in the consumption of zucchini (Cucurbita pepo L.) among the Portuguese population, which led to increased production of this vegetable. The total cultivated area (open field and greenhouse) has increased significantly in recent years, attaining an area of 615 ha in 2014; the area decreased in 2015 to 446 ha, but maintained approximately the same total yield (about 18,000 t) (INE, 2016).

During winter, there is a deficit of production, but in summer production is higher than demand, allowing exportation. At present, there is a positive ratio between zucchini annual exportation/importation values. This means that it is an attractive crop for farmers, especially in the western region of Portugal, which has a microclimate favourable for this crop. In addition, production in greenhouses allows two crops in the same year. The mild winter conditions of the region allow crop growth in unheated greenhouses, naturally ventilated, which is an advantage for reducing production costs and energy consumption

${ }^{\mathrm{a} E}$ E-mail: fb@uevora.pt 